\title{
Assessment of Anterior Cruciate Ligament Tibial Footprint Sagittal Diameter and Orientation of the Ligament in the Intercondylar Notch in Indian Population: A Magnetic Resonance Imaging (MRI) Analysis
} Aman Verma ${ }^{1}$

1. Orthopaedics, All India Institute of Medical Sciences Rishikesh, Rishikesh, IND

Corresponding author: Balgovind S. Raja, balgovindsraja@gmail.com

\begin{abstract}
Aim: To study the relevant anatomy of anterior cruciate ligament tibial footprint and orientation of the ligament in the intercondylar roof in Indian population the using MRI.
\end{abstract}

Methods: A total of 70 knee MRI with intact anterior cruciate ligament (ACL) was assessed for intercondylar roof angle, ACL inclination angle, ACL-bluemensaat angle, ACL sagittal center, and tibial insertion size.

Results: The ACL tibial sagittal center was found to be at $43.5 \%$ of the anteroposterior tibial length. Tibial insertion size averaged $15.40( \pm 1.29) \mathrm{mm}$ with no significant difference in males and females $(p>0.05)$. The roof angle was $36.29( \pm 4.02)^{\circ}$ and the ACL inclination angle and ACL-bluemensaat angle were $51.22( \pm 3.39)$ ${ }^{\circ}$ and $4.70( \pm 3.35)^{\circ}$ respectively with no significant sex difference $(p>0.05)$.

Conclusion: The ACL tibial insertion size averaged $15.40 \mathrm{~mm}$ and its center was at $43.51 \%$ along the Staubli and Rauschning line. The mean roof angle was 36.29 degrees and the ACL-bluemensaat angle was 4.70 degrees. Understanding of the tibial footprint morphology and the relation of the ligament to the roof of the intercondylar notch helps in anatomical graft placement during reconstruction.

Received 03/04/2020

Review began 03/06/2020 Review ended 03/27/2020 Published 04/02/2020

\section{() Copyright 2020}

Raja et al. This is an open access article distributed under the terms of the Creative Commons Attribution License CC-BY 4.0., which permits unrestricted use, distribution, and reproduction in any medium, provided the original author and source are credited.
Categories: Orthopedics

Keywords: anterior cruciate ligament, sagittal centre, tibial foot print, roof angle, acl inclination angle, aclbluemensaat angle

\section{Introduction}

Incidences of ligament injuries in the population are on the rise due to increased involvement in sports activities [1]. Anterior cruciate ligament (ACL) tears are among the most common ligament injuries in the knee joint and usually are seen secondary to excessive valgus stress, forced external rotation of the femur on a fixed tibia, and hyperextension [2]. Reconstruction of ACL owing to innovations in surgical instruments and improved surgical techniques is widely performed and understanding the anatomy of the ACL tibial footprint, the orientation of the ligament in relation to the roof of the intercondylar fossa and the tibial surface helps in precise anatomical placement of the graft in ACL reconstruction [3-5].

Ethnic variations in Indian knees have been thoroughly documented. Vaidya et al. observed the variations in dimensions of the bone geometry in the Indian scenario and Mullaji et al. documented the rotational axes differences of the distal femur in relation to the Caucasian population [6-7]. Though the anatomy of the ACL is well defined in literature, currently in the Indian scenario there appears to be little literature regarding the orientation of native ACL in the intercondylar notch and its tibial foot anatomy. A comprehensive idea regarding the tibial insertion anatomy, its variations along with relations of ACL to the intercondylar roof, and its inclination to the tibial surface will guide the surgeon to achieve an accurate and impingement-free graft placement.

The purpose of our study was to analyze the native ACL relations to roof of the intercondylar fossa, tibial surface and to assess the distal tibial insertion site morphology using MRI in the Indian population.

\section{Materials And Methods}

The study included 70 skeletally mature subjects (40 males and 30 females) selected retrospectively with normal knee MRI after the approval from the ethics committee (IEC2/OUT/44/18). Exclusion criteria included knees with osteoarthritic changes (Kellgren-Lawrence grade $\geqslant 2$ ), presence of epiphyseal line, concomitant ligament injuries, abnormalities of extensor mechanism, history of previous surgery or fractures around 


\section{Cureus}

knee, and history of patellar dislocation or subluxation. MRI was performed employing $1.5 \mathrm{~T}$ scanner with proton density fat suppression, coronal plane, $4 \mathrm{~mm}$ slice thickness, $0.5 \mathrm{~mm}$ space, matrix of $352 \times 224,13.6$ ms echo time, and repetition time of 1700-2000 ms. Sagittal and axial images, thickness of $3.5 \mathrm{~mm}$, space of $0.5 \mathrm{~mm}$, matrix of $352 \times 224$, echo time of $86 \mathrm{~ms}$, repetition time of $4200 \mathrm{~ms}$ with the knees in near normal extension.

Sagittal T2W slice in which the ACL tibial insertion fibers are well seen was selected for determining the relations of ACL. Femoral and tibial axes were drawn first joining the midpoints of two lines in their respective diaphysis. The angle made by the bluemensaat line and the femoral axis is defined as the roof angle [8] (Figure 1) and the ACL-bluemensaat angle refers to the angle formed by the bluemensaat line and the tangent to the anterior aspect of the anterior cruciate ligament (Figure 1) [9]. The ACL inclination angle is formed by the tangent to the anterior aspect of the ACL fibers and the perpendicular to the tibial axis at the ACL insertion site [10] (Figure 1). Femoral and tibial axes are drawn joining the midpoints of two lines in their respective diaphysis.

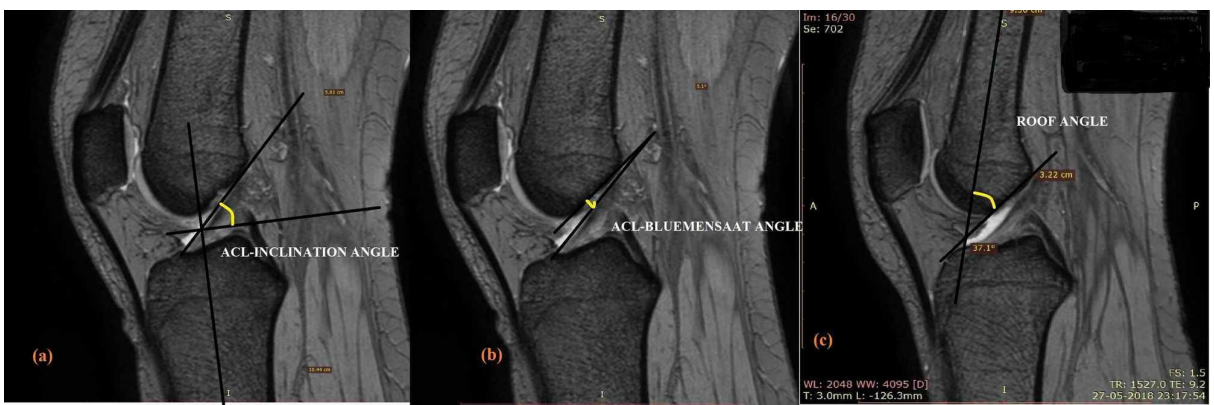

FIGURE 1: Illustrations showing measurement of ACL-inclination angle, ACL-bluemensaat angle, and roof angle.

T2 sagittal image slices showing the ACL (anterior cruciate ligament) relationship. (a) Angle between the tangent to the anterior aspect of the ACL and the perpendicular to the tibial axis is the ACL-inclination angle;

(b) ACL-bluemensaat angle is formed by the blumensaat line and the tangent to the anterior aspect of ACL;

(c) angle measure between the femoral axis and bluemensaat line gives roof angle.

Both T1- and T2- weighted sequences on the sagittal projection were evaluated to discover the ACL tibial insertion size and sagittal ACL tibial center. The sagittal slice that contained the largest tibial footprint was selected. The length along the Staubli and Rauschning line refers to the insertion site length (Figure 2). The percentage of the anteroposterior length from the anterior tibial cortex to the center of the ACL along the Staubli and Rauschningline gives sagittal ACL center (Figure 2) [10].
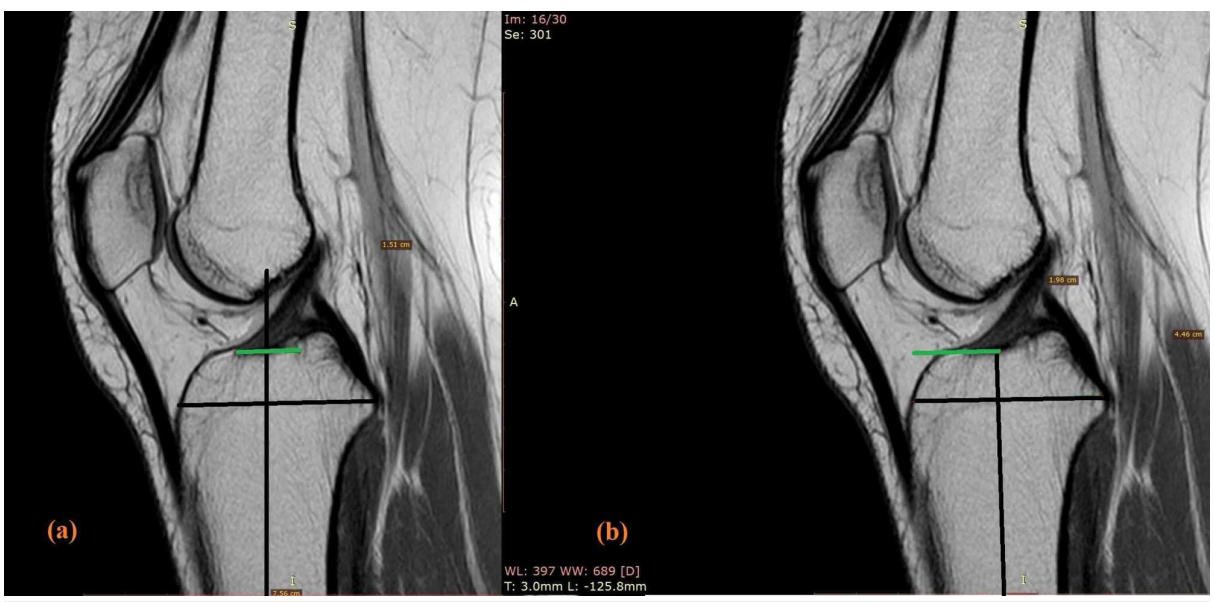

\section{FIGURE 2: T1 sagittal slices showing ACL tibial footprint anatomy.}

The tibial foot print sagittal length is measured along the Staubli and Rauschning line (a) and the ACL (anterior cruciate ligament) sagittal center is measured from the anterior aspect to the center of ACL tibial footprint along the same line (b) and is expressed as percentage. 


\section{Cureus}

data obtained were assessed using Microscoft Excel software and XL STAT software. Shapiro-Wilk test was used to assess the normality of the sample and Student's $t$ test was employed to compare the difference between genders. The values were expressed as mean $+/$ - standard deviation and a p value of $<0.05$ was considered statistically significant.

\section{Results}

The average age of the subjects was 35 with $18-51$ years range. The roof angle was $36.29( \pm 4.02)^{\circ}$ with no significant difference in males and females ( $\mathrm{p}>0.05$ ), (Table 1). The ACL inclination angle averaged 51.22 $( \pm 3.39)^{\circ}$ with $51.72( \pm 3.16)^{\circ}$ in males and $50.53( \pm 3.66)^{\circ}$ in females respectively $(\mathrm{p}>0.05)$. The mean ACLbluemensaat angle was found out to be $4.70( \pm 3.35)^{\circ}$ with no significant difference between the sexes $(\mathrm{p}>$ 0.05). Tibial insertion site was found out to be $15.40+/-1.29$ along the Staubli and Rauschning line with $15.63+/-1.47$ in males and 15.08+/-0.92 in females respectively $(\mathrm{p}>0.05)$. The ACL sagittal center averaged $43.51 \%+/-3.1$ from the anterior cortex along the same reference line with $43.72 \%+/-3.3$ in males and $43.22 \%+/-2.9$ in females (Table 1$),(p>0.05)$.

\begin{tabular}{|c|c|c|c|c|}
\hline Parameters & Male & Female & Total & p value ${ }^{\star \star}$ \\
\hline Number of subjects & 40 & 30 & 70 & - \\
\hline \multicolumn{5}{|l|}{ Roof angle $^{\circ}$} \\
\hline Mean & 36.96 & 35.36 & 36.29 & 0.059 \\
\hline Standard deviation & 3.90 & 4.09 & 4.02 & \\
\hline \multicolumn{5}{|l|}{ ACL-inclination angle ${ }^{\circ}$} \\
\hline Mean & 51.72 & 50.53 & 51.22 & 0.240 \\
\hline Standard deviation & 3.16 & 3.66 & 3.39 & \\
\hline \multicolumn{5}{|c|}{ ACL-bluemensaat angle ${ }^{\circ}$} \\
\hline Mean & 4.66 & 4.75 & 4.70 & 0.384 \\
\hline Standard deviation & 3.47 & 3.25 & 3.35 & \\
\hline \multicolumn{5}{|l|}{ Tibial insertion site* } \\
\hline Mean & 15.63 & 15.08 & 15.40 & 0.067 \\
\hline Standard deviation & 1.47 & 0.92 & 1.29 & \\
\hline \multicolumn{5}{|c|}{ ACL tibial footprint sagittal center } \\
\hline Mean & $43.72 \%$ & $43.22 \%$ & $43.51 \%$ & 0.781 \\
\hline Standard deviation & 3.3 & 2.9 & 3.1 & \\
\hline
\end{tabular}

TABLE 1: Patient demographics and study results.

*Length measured along the anteroposterior diameter of proximal tibia in millimeters, ${ }^{\star *} p$ value $<0.05$ is significant. ACL, anterior cruciate ligament.

\section{Discussion}

The principal findings of our study include: a) The ACL tibial footprint sagittal center averaged $43.51 \%$ along the AP width of tibia; b) The average ACL tibial footprint sagittal insertion length was $15.4 \mathrm{~mm}$; c) The intercondylar roof angle averaged $36.29^{\circ}$; d) The ACL-inclination angle and ACL-bluemensaat angle averaged $51.22^{\circ}$ and $4.70^{\circ}$ respectively.

The proper placement of the tibial tunnel during ACL reconstruction is essential as it would minimize complications like graft impingement, instability, loss of knee extension, and anterior knee pain [11-12]. Howell and Major in their study advocated the ideal tibial tunnel placement to be $44 \%$ of the anteroposterior diameter of joint line [11]. Iriuchishima et al. in his study reckoned that if the graft is being placed in anatomic position, with single or double bundle reconstruction techniques the resultant knees experienced an impingement-free environment and more biomechanical stability [13]. A posteriorly placed tunnel would result in a vertically oriented graft which may not provide rotational stability [12]. An anteriorly placed tibial tunnel would lead to a more horizontal graft and in turn lead to impingement and graft failures. The 
understanding of the tibial insertion site becomes even more necessary in revision cases where the footprint anatomy may be altered. There is currently no literature on ACL tibial footprint morphology in Indian population. Our study revealed the tibial footprint to be about $43.51 \% \pm 3.1$ from the anterior tibial cortex along the Staubli and Rauschning line. It is in accordance with the previous studies (Table 2) and was noted to be more than $40 \%$ as per Cho et al. study in the East Asian population [14]. It would be advisable to keep the center of the tibial tunnel during single bundle reconstruction between the range $37.31 \%$ and $49.71 \%$ $($ mean $\pm 2 \mathrm{SD})$ as it would help in preventing a very anterior or posteriorly placed graft. This will be extremely practical in revision cases and one needs to be careful in revision of cases wherein the tunnels that are outside this range.

\begin{tabular}{|c|c|c|c|c|c|c|}
\hline & $\begin{array}{l}\text { Our } \\
\text { study }\end{array}$ & $\begin{array}{l}\text { Ichiba et al. } \\
\text { [21] }\end{array}$ & Kim et al. & $\begin{array}{l}\text { Frank et al. } \\
{[22]}\end{array}$ & $\begin{array}{l}\text { Scheffel et } \\
\text { al. }\end{array}$ & Staubli et al. \\
\hline Place of study & India & Japan & South Korea & USA & USA & \\
\hline Method & MRI & MRI & MRI & MRI & MRI & MRA \\
\hline Sample size & 70 & 100 & 164 & 100 & 138 & 35 \\
\hline $\begin{array}{l}\text { ACL sagittal insertion size } \\
\text { mean* }^{\star}\end{array}$ & 15.40 & 15.2 & 12.4 & - & - & - \\
\hline Standard deviation & 1.39 & 1.9 & $\begin{array}{l}\text { Not } \\
\text { mentioned }\end{array}$ & - & - & - \\
\hline p value ${ }^{\star \star}$ & & 0.453 & - & - & - & - \\
\hline ACL sagittal center mean (\%) & 43.51 & - & - & 46 & 44.1 & $\begin{array}{l}\text { 44.1-males 43.7- } \\
\text { females }\end{array}$ \\
\hline Standard deviation & 3.1 & - & - & 4 & 3.4 & Not mentioned \\
\hline$p$ value ${ }^{\star \star}$ & & - & - & $<0.001$ & 0.228 & - \\
\hline
\end{tabular}

\section{TABLE 2: Summary of literature on ACL tibial footprint.}

*Value in mm. ${ }^{\star}$ Value $<0.05$ is significant. ACL, anterior cruciate ligament; MRA, magnetic resonance arthrography.

Tibial insertion sites of sagittal diameter < $14 \mathrm{~mm}$ favor single bundle reconstruction over double bundle reconstruction, whereas the double bundle reconstruction is typically done when the insertion sites are $>14$ $\mathrm{mm}$ [15]. Our study revealed the tibial insertion site to be $15.40+/-1.29 \mathrm{~mm}$ with no statistical difference between the genders (Table 1). Staubli et al. recorded similar mean tibial insertion size to ours [10].To our best knowledge this is the first study that assesses the tibial footprint anatomy in Indian population.

Illingworth et al. quoted the use of the femoral tunnel angle measured in weight-bearing X-rays and patient's native ACL inclination angles to assess the anatomic placement of tunnels in ACL reconstruction [16]. Gentili et al. noticed a mean angle of $55.6^{\circ}$ and Kim et al. found out $55.5+/-6.7^{\circ}$ in females and $53.9+/-5.8^{\circ}$ in males for native ACL $[9,17]$. Ayerza et al. suggested the sagittal graft inclination angles to be essentially higher than intact ACL [18]. An increased inclination angle paralleled with nonanatomically placed grafts. A value of $55^{\circ}$ or more was considered as a reliable predictor for nonanatomic placement of femoral tunnel [16]. The inclination angle found in our study population was $51.22+/-3.39^{\circ}$ (Table 1).

For the graft to enjoy an impingement-free environment, it should be placed in an anatomic position wherein it will be almost parallel to the intercondylar roof. The impingement of the ACL against the roof constitutes the primary mechanism of tears [4]. An increase in roof angle makes the ACL relatively more horizontal which may lead to frequent ruptures in extension due to impingement against the anterior part of the intercondylar notch. A decreased roof angle has ACL in a more vertical position wherein, narrow intercondylar notch may represent the cause of impingement [19].

The ACL-bluemensaat angle relates to the relationship between the roof and the graft. A decreased angle may suggest an anteriorly placed tibial tunnel where the graft is almost parallel to the bluemensaat line or the roof of the intercondylar notch. The angle is considered as an indirect sign for ACL tear in MRI. Gentili et al. recorded the angle to be $1.6^{\circ}$ whereas, Saxena et al. found it to be $7.06^{\circ}[9,20]$. The only notable study that relates the antecedent parameter in Indian population is by Saxena et al. [20]. The value of their study is questionable when one considers the number of subjects (normal) $n=23$ they included in the normal group. Our study revealed the mean angle to be $4.70+/-3.35^{\circ}$ with no significant difference between males and 
females (Table 1). Summary of studies concerning the present study is produced in Tables 2 and 3 .

\begin{tabular}{|c|c|c|c|c|c|}
\hline & Our study & Scheffel et al. & Saxena et al. & Gentili et al. & Ayerza et al. \\
\hline Place of study & India & USA & India & USA & Argentina \\
\hline Method & MRI & MRI & MRI & MRI & MRI \\
\hline Sample size & 70 & 138 & 24 & 35 & 30 \\
\hline Roof angle mean ${ }^{\circ}$ & 36.29 & 34.7 & 44.24 & - & - \\
\hline Standard deviation & 4.02 & 5.2 & 3.64 & - & - \\
\hline p value ${ }^{*}$ & & 0.026 & $<0.001$ & - & - \\
\hline ACL-inclination angle mean ${ }^{\circ}$ & 51.22 & - & 51.34 & 55.6 & 51 \\
\hline Standard deviation & 3.39 & - & 3.99 & Not mentioned & Not mentioned \\
\hline p value ${ }^{*}$ & & - & 0.886 & - & - \\
\hline ACL-bluemensaat angle mean ${ }^{\circ}$ & 4.70 & - & 7.06 & 1.6 & - \\
\hline Standard deviation & 3.35 & - & 1.44 & Not mentioned & - \\
\hline p value ${ }^{*}$ & & - & 0.0012 & - & - \\
\hline
\end{tabular}

TABLE 3: Summary of literature related to $A C L$ relation within knee.

*Value $<0.05$ is significant. ACL, anterior cruciate ligament.

The study has its own limitations. First, patient height and weight were not recorded as the study was retrospective in nature. Second, the femoral insertion site morphology and ACL medio-lateral width being difficult to appreciate in MRI could not be measured. Third, our study measurements were recorded by a single examiner; ideally 2-3 examiners are needed. Last, further studies with larger sample population are required to understand the morphology better.

\section{Conclusions}

The anteroposterior diameter of the ACL tibial footprint in Indian population is comparable to the western population. The tibial insertion site diameter averaged $15.40 \mathrm{~mm}$ and the center of the tibial insertion was found to be at an average of $43.51 \%$ along the Staubli and Rauschning line. The mean roof angle was 36.29 degrees and the ACL-bluemensaat angle averaged 4.70 degrees. Understanding of the tibial footprint morphology and the orientation of the ligament to the roof of the intercondylar notch help in anatomical graft placement during reconstruction.

\section{Additional Information}

\section{Disclosures}

Human subjects: Consent was obtained by all participants in this study. Institutional ethics committee, Seth GS Medical college and KEM hospital issued approval IEC (2)/OUT/44/18. The IEC-2 of the college has approved the protocol submitted titled epidemiology of anterior cruciate ligament tears and meniscal injuries at a tertiary care center in western India. Animal subjects: All authors have confirmed that this study did not involve animal subjects or tissue. Conflicts of interest: In compliance with the ICMJE uniform disclosure form, all authors declare the following: Payment/services info: All authors have declared that no financial support was received from any organization for the submitted work. Financial relationships: All authors have declared that they have no financial relationships at present or within the previous three years with any organizations that might have an interest in the submitted work. Other relationships: All authors have declared that there are no other relationships or activities that could appear to have influenced the submitted work.

\section{Acknowledgements}

Dr S S Bawa (Professor, Department of Orthopaedics, Seth GS Medical College and KEM hospital Mumbai) Dr Swapneel Shah (Junior resident, Department of Orthopaedics, Seth GS Medical College and KEM Hospital, Mumbai) 


\section{References}

1. Dragoo JL, Braun HJ, Durham JL, Chen MR, Harris AH: Incidence and risk factors for injuries to the anterior cruciate ligament in National Collegiate Athletic Association football: data from the 2004-2005 through 2008-2009 National Collegiate Athletic Association Injury Surveillance System. Am J Sports Med. 2012, 40:990-995.

2. Griffin LY, Agel J, Albohm MJ, Arendt EA, Dick RW, Garrett WE: Noncontact anterior cruciate ligament injuries: risk factors and prevention strategies. J Am Acad Orthop Surg. 2000, 8:141-50.

3. Ejerhed L, Kartus J, Sernert N, Kohler K, Karlsson J: Patellar tendon or semitendinosus tendon autografts for anterior cruciate ligament reconstruction? A prospective randomized study with a two-year follow-up. Am J Sports Med. 2003, 31:19-25.

4. Fu FH, Shen W, Starman JS, Okeke N, Irrgang JJ: Primary anatomic double-bundle anterior cruciate ligament reconstruction: a preliminary 2-year prospective study. Am J Sports Med. 2008, 36:1263-1274.

5. Yasuda K, Kondo E, Ichiyama H, Kitamura N, Tanabe Y, Tohyama H, Minami A: Anatomic reconstruction of the anteromedial and posterolateral bundles of the anterior cruciate ligament using hamstring tendon grafts. Arthroscopy. 2004, 20:1015-1025.

6. Vaidya SV, Ranawat CS, Aroojis A, Laud NS: Anthropometric measurements to design total knee prostheses for the Indian population. J Arthroplasty. 2000, 15:79-85.

7. Mullaji AB, Sharma AK, Marawar SV, Kohli AF, Singh DP: Distal femoral rotational axes in Indian knees . J Orthop Surg. 2009, 17:166-169.

8. Scheffel PT, Henninger HB, Burks RT: Relationship of the intercondylar roof and the tibial footprint of the ACL: implications for ACL reconstruction. Am J Sports Med. 2013, 41:396-401.

9. Gentili A, Seeger LL, Yao L, Do HM: Anterior cruciate ligament tear: indirect signs at MR imaging . Radiology. 1994, 193:835-840.

10. Stäubli HU, Rauschning W: Tibial attachment area of the anterior cruciate ligament in the extended knee position. Anatomy and cryosections in vitro complemented by magnetic resonance arthrography in vivo. Knee Surg Sports Traumatol Arthrosc. 1994, 2:138-146.

11. Howell SM, Taylor MA: Failure of reconstruction of the anterior cruciate ligament due to impingement by intercondylar roof. J Bone Joint Surg. 1993, 75:1044-1055. https://doi.org/10.2106/00004623-19930700000011

12. Bedi A, Maak T, Musahl V, Citak M, O'Loughlin PF, Choi D, Pearle AD: Effect of tibial tunnel position on stability of the knee after anterior cruciate ligament reconstruction: is the tibial tunnel position most important?. Am J Sports Med. 2011, 39:366-373.

13. Iriuchishima T, Ingham SJ, Tajima G, et al.: Evaluation of the tunnel placement in the anatomical doublebundle ACL reconstruction: a cadaver study. Knee Surg Sports Traumatol Arthrosc. 2010, 2010:1226-1231.

14. Cho HJ, Kim TK, Kang S-B, Do MU, Chang CB: Variations in sagittal locations of anterior cruciate ligament tibial footprints and their association with radiographic landmarks: a human cadaveric study. BMC Musculoskeletal Disord. 2017, 18:448.

15. van Eck CF, Lesniak BP, Schreiber VM, Fu FH: Anatomic single- and double-bundle anterior cruciate ligament reconstruction flowchart. Arthroscopy. 2010, 26:258-268.

16. Illingworth KD, Hensler D, Working ZM, Macalena JA, Tashman S, Fu FH: A simple evaluation of anterior cruciate ligament femoral tunnel position: the inclination angle and femoral tunnel angle. Am J Sports Med. 2011, 39:2611-2618.

17. Kim HK, Laor T, Shire NJ, Bean JA, Dardzinski BJ: Anterior and posterior cruciate ligaments at different patient ages: MR imaging findings. Radiology. 2008, 247:826-835.

18. Ayerza MA, Muscolo DL, Costa-Paz M, Makino A, Rondon L: Comparison of sagittal obliquity of the reconstructed anterior cruciate ligament with native anterior cruciate ligament using magnetic resonance imaging. Arthroscopy. 2003, 19:257-261.

19. Fernández-Jaén T, López-Alcorocho JM, Rodriguez-Iñigo E, Castellán F, Hernández JC, Guillén-García P: The importance of the intercondylar notch in anterior cruciate ligament tears . Orthop J Sports Med. 2015, 3:2325967115597882. 10.1177/2325967115597882

20. Saxena A, Ray B, Rajagopal K, D'Souza S: Morphometry and magnetic resonance imaging of anterior cruciate ligament and measurement of secondary signs of anterior cruciate ligament tear. Bratislavskélekárskelisty. 2012, 113:539-543.

21. Ichiba A, Kido H, Tokuyama F, Makuya K, Oda K: Sagittal view of the tibial attachment of the anterior cruciate ligament on magnetic resonance imaging and the relationship between anterior cruciate ligament size and the physical characteristics of patients. J Orthop Sci. 2014 Jan, 19:97-103. 10.1007/s00776-0130479-x

22. Frank RM, Seroyer ST, Lewis PB, Bach BR Jr, Verma NN: MRI analysis of tibial position of the anterior cruciate ligament. Knee Surg Sports Traumatol Arthrosc. 2010, 18:1607-1611. 10.1007/s00167-010-1192-3 